\title{
Novos meridianos da produção editorial em castelhano \\ o papel de espanhóis exilados pela Guerra Civil na Argentina e no México*
}

\author{
New axes of editorial \\ production in Castilian \\ the role of Spanish civil war exiles \\ in Argentina and Mexico
}

\author{
G ABRIELA PELLEGRINO SOARES \\ Professora do Departamento de História da \\ FFLCH-USP - Universidade de São Paulo \\ Doutora em História Social pela Universidade de São Paulo \\ gabriela.pellegrino@ terra.com.br
}

\begin{abstract}
RESUMO Este artigo tem por objetivo lançar luz sobre o impacto da Guerra Civil Espanhola sobre a indústria editorial argentina e mexicana. Em particular, pretende enfocar as contribuições oferecidas por refugiados ou exilados espanhóis que, uma vez estabelecidos na outra margem do Atlântico, procuraram retomar seus ofícios de origem, inserindo-se nas gráficas e editoras existentes nesses dois países ou fundando novos negócios livreiros. Tanto o México como, em especial, a Argentina, beneficiaram-se da crise impingida pela guerra à indústria editorial da antiga metrópole para explorar o vasto mercado aberto aos impressos em língua espanhola.
\end{abstract}

Palavras-chave Guerra Civil Espanhola, Argentina, México, mercado editorial

\footnotetext{
Artigo recebido em 01/08/2007. Autora convidada.
} 
ABSTRACT This article aims at shedding light on the impact of the Spanish Civil War on the publishing industry in Argentina and in Mexico. Particularly, it intends to analyze the contributions of Spanish refugees or in exile who, once established on the other border of the Atlantic Ocean, tried to go back to their previous jobs, working at preexisting publishing houses in those two countries or creating new ones. Both Mexico and specially Argentina took advantage of the Spanish publishing industry's crises so to explore the vast business opportunities for books in Spanish.

Key words Spanish Civil War, Argentina, Mexico, publishing market

\section{Os refugiados da Guerra Civil Espanhola: da França ao Novo Mundo}

Desde o início da Guerra Civil, em 1936, levas de refugiados transpuseram as fronteiras da Espanha em busca de salvaguarda temporária. 0 volume de pessoas rumando para o exílio cresceu sensivelmente nos meses anteriores à vitória das forças franquistas, as quais, em fins de janeiro de 1939, dominaram a Catalunha e, pouco tempo depois, Madri. Acuados, combatentes republicanos, suas famílias e simpatizantes procuraram alcançar a França através dos Pirineus. Em princípios de 1939, para se ter uma idéia, 500 mil pessoas ingressaram no território vizinho por essa rota, em um lapso de apenas 18 dias.

O país que mais recebeu refugiados espanhóis nesse período procurou apresentar respostas rápidas - e duras - ao problema social e diplomático que se criava. Os recém-chegados foram confinados em diferentes campos estabelecidos próximos à fronteira. Aos poucos, mulheres e crianças foram transferidas para albergues com melhores condições de alojamento. Ainda assim, a decepção foi generalizada diante da acolhida oferecida pelas autoridades da agonizante III República, que não poupava os adversários do Franquismo de sofrer novas agruras causadas pela fome e o frio. ${ }^{1}$

De sua parte, a diplomacia francesa estava nesse momento empenhada em aproximar-se de Franco, de modo a evitar que o território nacional fosse comprimido por um cinturão nazi-franquista. As manobras simbólicas exigiam um tratamento discreto ao problema dos refugiados republicanos, de forma a evitar que a imagem da França fosse associada à causa dos inimigos vencidos pelos nacionalistas espanhóis.

Pouco a pouco, dentre as soluções encontradas para os impasses sociais e diplomáticos, a França procurou negociar o retorno de parte dos

1 Ver SCHWARZSTEIN, Dora. Entre Franco y Perón: memoria y identidad del exilio republicano español en Argentina. Barcelona: Crítica, 2001. 
refugiados à Espanha - não raro, por meio de repatriações forçadas -, e sua emigração para outros continentes, em especial, para países do Norte da África e da América Hispânica, esta última o universo a que este artigo se detém. ${ }^{2}$

A perspectiva de traslado às ex-colônias gerou resistência não só entre os refugiados, que em geral consideravam transitório o exílio da terra natal, como entre muitos dos Estados hispano-americanos, temerosos da coloração política dos grupos a serem acolhidos.

No caso da Argentina, os governos conservadores que dominaram a cena nos anos 1930 e princípios dos anos 1940 adotaram políticas que restringiam e dificultavam a entrada de refugiados da Guerra Civil na Espanha. A política seletiva visava, por um lado, coibir a vinda de possíveis perturbadores da ordem e, por outro, atender às metas de desenvolvimento econômico, insistindo em uma perspectiva sobre a imigração, herdada do século XIX, que valorizava a figura do agricultor. ${ }^{3} \mathrm{Em}$ vista dos critérios empregados, poucos cidadãos espanhóis obtiveram asilo no país. A política oficial, todavia, não impediu que um volume muito maior de refugiados ingressasse e se estabelecesse informalmente na Argentina, com o apoio, como veremos, de diferentes associações e iniciativas civis.

Já o México, então presidido por Lázaro Cárdenas, destoou da maioria de seus vizinhos continentais ao abrir os braços para os representantes da luta contra o fascismo na Espanha. ${ }^{4}$ Dentre os esforços oficiais levados a cabo para acolher os refugiados, destaca-se o conhecido caso dos "niños de Morelia", a quem, a partir de meados de 1937, o governo mexicano proporcionou proteção enquanto seus pais se expunham aos perigos da Guerra Civil. Recepcionadas no porto de Vera Cruz pela primeira-dama Amalia Solórzano, as 456 crianças foram abrigadas em uma escola em Morelia, no estado de Michoacán, à espera do fim do confronto.

Às políticas governamentais somaram-se iniciativas de intelectuais de prestígio, solidários à causa republicana, e de organismos de auxílio empenhados em intermediar o envio de refugiados à América Latina. Dentre outros, a SERE (Senvicio de Emigración de Refugiados Españoles) e a

2 Dada a heterogeneidade e transitoriedade dos enquadramentos legais aplicados aos espanhóis que desembarcaram na América Espanhola nos anos 1930 e 1940, em conseqüência da Guerra Civil na Espanha e do regime instaurado pelo general Franco, não farei aqui um uso juridicamente preciso dos termos "refugiados", "asilados" ou "exilados".

3 Cf. SCHWARZSTEIN, Dora. Entre Franco y Perón: memoria y identidad del exilio republicano español en Argentina. Barcelona: Crítica, 2001, p.66.

4 Também o Chile, após eleição de Pedro Aguirre Cerda, candidato da Frente Popular, em 1938, mostrou-se receptivo aos espanhóis republicanos, empenhando-se em trasladar refugiados, sobretudo por intermediação do poeta Pablo Neruda, que pouco tempo antes desempenhara a função de cônsul de seu país na Espanha. Após a morte de Federico García Lorca, Neruda voltou a apresentar-se ao presidente chileno, assumindo a missão oficial de apoiar a emigração de refugiados espanhóis junto à embaixada chilena em Paris. Em setembro de 1939, logo após o irromper da II Guerra Mundial, 2200 republicanos embarcados no Winnipeg aportaram em Valparaíso. Tratou-se da maior expedição de exilados espanhóis a cruzar o Atlântico. Atrás do México e do Chile, a República Dominicana, então governada pelo ditador Rafael Leónidas Trujillo, foi o terceiro país a mais receber refugiados da Guerra Civil na Espanha. 
JARE (J unta de Auxilio a los Republicanos Españoles) contribuíram para que o México fosse a nação hispano-americana a receber o maior número de espanhóis refugiados da Guerra Civil. As negociações que esses organismos estabeleceram com o governo mexicano foram facilitadas pelo ex-secretário da educação do México, Narciso Bassols, embaixador de seu país em Paris.

Sediada na capital francesa, a SERE estava vinculada aos partidos de esquerda envolvidos na luta contra o Franquismo e foi contemplada com a missão de gerir os fundos enviados pelo governo republicano ao exterior. Juan Negrín, presidente honorário da SERE, embarcou parte desse tesouro no iate Vita com destino ao México, onde seria custodiado pelo governo de Cárdenas. Recebido no porto de Veracruz pelo socialista Indalecio Prieto, o tesouro esteve na origem da criação da JARE - com sede em Paris e representação no México - e seria de grande valia para apoiar o traslado de republicanos espanhóis ao exílio.

As organizações tais como a SERE cuidavam de "selecionar" a mãode-obra especializada a fim de corresponder às demandas específicas de países interessados em incorporá-la. Intelectuais e líderes sindicais ligados a organizações republicanas foram beneficiados nesses processos de seleção, o que teve como contrapartida o fato de que muitos refugiados menos qualificados e politicamente menos enfronhados fossem abandonados à própria sorte na França da II Guerra, vulneráveis aos arbítrios da ocupação nazista.

\section{Argentina e México: um perfil dos exilados}

Em face dos empecilhos colocados pelo governo da Argentina para a concessão de asilo a republicanos espanhóis, o país recebeu sobretudo refugiados que não conseguiram se enquadrar nos envios organizados por organismos de auxílio. Vista como "terra prometida" por sua prosperidade econômica e cultural, a Argentina continuou a atrair espanhóis nos anos que se seguiram à Guerra Civil, egressos dos campos de refugiados na França, das perseguições franquistas na Espanha e do avanço nazista na Europa.

A despeito da política oficial contrária à sua acolhida, os espanhóis em busca de um lugar seguro para si no mundo, lá encontraram uma sociedade mobilizada a seu favor. Em fevereiro de 1939, antes que o final da Guerra Civil fosse selado, o governo argentino reconheceu a vitória das forças nacionalistas. A atitude foi condenada por diversos setores da sociedade argentina, incluindo a vasta comunidade de imigrantes espanhóis que fora se formando desde as últimas décadas do século XIX. Por meio da imprensa e de associações com identidade regionalista (asturiana, andaluz, galega e assim por diante), desenharam-se estratégias de apoio aos republicanos, 
ao mesmo tempo em que a comunidade imigrante partidária dessa causa reproduzia, nos espaços públicos do país em que se havia fincado, a atmosfera de polarização política em face dos concidadãos franquistas. ${ }^{5}$

Determinados acontecimentos ajudaram a conferir contornos nítidos à mobilização argentina simpática aos refugiados. Em novembro de 1939, por exemplo, o vapor Massilia atracou no porto de Buenos Aires transportando 147 intelectuais republicanos. Os passageiros deviam aguardar a bordo até o momento do embarque nos trens que os levariam ao Chile e, uma pequena parte deles, ao Paraguai e à Bolívia. Durante a espera, os refugiados receberam a visita de Natalio Botana, diretor do jornal Critica, que Ihes doou o dinheiro de um prêmio que seu cavalo arrematara no J ockey Club e a verba reunida em uma campanha promovida pelo periódico. Ao mesmo tempo, Natalio Botana encabeçou as pressões para que o então presidente da República Argentina, Ortiz Rubio, autorizasse a permanência no país dos passageiros que assim o desejassem. Objeto de muitas especulações sobre as motivações envolvidas, a autorização foi afinal concedida. ${ }^{6}$

Meses antes do episódio desencadeado pela chegada do Massilia, formara-se em Buenos Aires uma Comisión Argentina de Ayuda a los Intelectuales Españoles, presidida por Francisco Romero e secretariada por Emilio Ravignani, Norberto Frontini e María Rosa Oliver. Outros intelectuais proeminentes vieram a integrar a Comissão, como Eduardo Mallea, Adolfo Bioy Casares e Silvina Ocampo. ${ }^{7}$

Vários desses escritores guardavam estreitas relações com a prestigiada Sur, dirigida por Victoria Ocampo, revista que normalmente se mantinha à parte das discussões políticas, mas que já em 1937 publicara um editorial intitulado Posición Sur, apoiando a luta contra todas as ditaduras e perseguições. ${ }^{8}$ Por meio de seus colaboradores, a revista alimentou de diferentes maneiras as redes de solidariedade que procuravam oferecer algum amparo aos refugiados espanhóis.

Por fim, também expressando as múltiplas iniciativas civis ou institucionais que ganhavam corpo na Argentina em face dos desterrados da Guerra Civil, a Instituição Cultural Espanhola propôs, em fins de 1938, a criação de uma Escola de Altos Estudos Hispânicos, ligada à Universidade de Buenos Aires. À imagem das Escolas de Altos Estudos existentes em Nova lorque,

5 A esse respeito, ver QUIJADA, Monica. Aires de República, aires de cruzada: la Guerra Civil Española en Argentina. Barcelona: Sendai Ediciones, 1991.

6 Ver BOTANA, Helvio. Memorias. Tras los dientes del perro. Buenos Aires: Ediciones A. Peña Lillo,1977.

7 Vale lembrar que a estadia de Federico García Lorca em Buenos Aires por cerca de cinco meses, entre 1933 e 1934, contribuiu para tecer redes de solidariedade entre a intelectualidade argentina e a causa republicana na Espanha. Ver MEDINA, Pablo. Un Andaluz en Buenos Aires, 1933-1934. Buenos Aires: Manrique Zago y León Goldstein, 1999.

8 Cf. HERMES VILLORDO, Oscar. El grupo SUR: una biografía colectiva. Buenos Aires: Planeta: Biografías del Sur, 1993. 
Berlim e Paris, a Escola argentina procuraria atrair acadêmicos espanhóis no exílio. ${ }^{9}$

Entretanto, seu alcance foi restrito, sobretudo em comparação aos sucessos mexicanos nesse campo, comentados adiante. Alguns acadêmicos chegaram a ser contratados por universidades das províncias, como o renomado pedagogo espanhol Lorenzo Luzuriaga, que atuou temporariamente na Universidade de Tucumán. Em 1943, todavia, em meio aos novos ventos políticos que sopravam em uma Argentina com inclinações nazi-fascistas, Luzuriaga transferiu-se para Buenos Aires a fim de dedicar-se à atividade editorial.

Sua escolha não foi casual. A comunidade republicana espanhola teria marcada presença no setor editorial, adquirindo na vida cultural e política da Argentina de meados do século XX um peso simbólico que se sobrepunha a seu peso numérico.

Diferentemente da sociedade argentina, na visão de Dora Schwarzstein, a sociedade mexicana foi mais reticente para com os refugiados espanhóis, reagindo à receptividade manifesta pelo governo. A imprensa e a opinião pública expressaram seu receio de que técnicos e intelectuais espanhóis viessem a ocupar o lugar dos trabalhadores nacionais, pressionando o governo a restringir o leque de profissionais cuja imigração seria facilitada. ${ }^{10}$

Apesar das pressões, além de ter sido o rumo tomado na América Hispânica pelo maior número de espanhóis egressos da Guerra Civil na Espanha, o México foi o país a receber, proporcionalmente, o maior número de indivíduos educados, dentre os quais intelectuais ligados à vida acadêmica e ao universo editorial. Foram importantes nesse sentido as mediações realizadas pelo intelectual e editor mexicano Daniel Cosío Villegas, estabelecido em Lisboa em 1937 para ocupar um posto junto à embaixada mexicana.

Ao lado do poeta Alfonso Reyes, Cosío Villegas foi responsável pela criação da Casa de España, logo rebatizada como Colegio de México, destinada a absorver, a exemplo das universidades norte-americanas que abriram as portas para cientistas alemães perseguidos pelo nazismo, acadêmicos espanhóis. Cosío Villegas previa que a Argentina, por ser um país rico e com grande infra-estrutura educacional, figuraria como destino preferencial de muitos deles. Por isso, concebeu uma forma de oferecer-lhes condições de trabalho convidativas no México.

Por sua vez, a Fondo de Cultura Económica, fundada por Daniel Cosío Villegas no México, em 1934, também representou um espaço privilegiado

9 Sobre as intervenções políticas que marcaram a trajetória da Universidade de Buenos Aires nas décadas de 1930 e 1940 ver HALPERIN DONGHI, Túlio. Historia de la Universidad de Buenos Aires. Buenos Aires: EUDEBA, 2002.

10 Cf. SCHWARZSTEIN, Dora. Entre Franco y Perón: memoria y identidad del exilio republicano español en Argentina. Barcelona: Crítica, 2001, p.37. 
de inserção profissional para muitos espanhóis refugiados, dos intelectuais à mão-de-obra especializada nas várias áreas do trabalho editorial. Assim como na Argentina, os recém-chegados contribuíram para impulsionar as editoras já estabelecidas no país e para fundar várias outras, embora essa renovação tenha ocorrido, comparativamente, em menor escala no México.

\section{Editores espanhóis na Argentina}

Já em fins do século XIX, a Argentina representava o terceiro país do mundo na relação de jornais existentes por habitante e, na década de 1920, como indicou Beatriz Sarlo em diferentes estudos, variadas revistas semanais eram vendidas, com elevadas tiragens, em bancas de jornal. ${ }^{11}$ Desde princípios do século XX, também a edição nacional de livros ganhou impulso, sendo a primeira coleção de sucesso lançada pelo jornal La Nación em 1901. A Biblioteca de La Nación editou 875 livros ao longo de 20 anos, ultrapassando a cifra de um milhão de exemplares vendidos. Tornou-se referência para uma série de iniciativas editoriais nos anos 1920 e 1930, inspiradas na concepção de "biblioteca" como um guia de leituras necessárias para distintos públicos que desejavam cultivar-se.

O estabelecimento em Buenos Aires de refugiados espanhóis com experiência em diferentes áreas da atividade editorial trouxe alento a uma indústria que já vinha florescendo no país. ${ }^{12}$ Em contrapartida, a crise das editoras espanholas, provocada pela Guerra Civil, abriu extraordinárias perspectivas de mercado às empresas portenhas, as quais fizeram da Argentina, entre fins dos anos 1930 e meados dos anos 1950, o mais importante centro editorial em língua hispânica do mundo.

Como observou Domingo Buonocore:

11 Ver, por exemplo, SARLO, B. El imperio de los sentimientos: narraciones de circulación periódica en la Argentina (1917-1927). Buenos Aires: Grupo Editorial Norma, 2000. Também em SARLO, B. Paisagens imaginárias: intelectuais, arte e meios de comunicação. São Paulo: EDUSP, 1997. O tema do mercado editorial argentino nas primeiras décadas do século XX foi mais amplamente tratado no meu livro SOARES, Gabriela Pellegrino. Semear horizontes: uma história da formação de leitores na Argentina e no Brasil, 1915-1954. Belo Horizonte: Editora UFMG, 2007. O tema também foi objeto do artigo de minha autoria SOARES, Gabriela Pellegrino. Conformando uma Argentina leitora: educação pública, bibliotecas e mercado editorial entre fins do século XIX e meados do século XX. História, São Paulo, Editora UNESP, v.22, nº.2, p.133-150, 2003.

12 No século XIX, o desenvolvimento do mercado editorial espanhol contou com a marcada atuação de empresas de origem francesa, que ao mesmo tempo serviam de referência e concorriam com as editoras nacionais. De acordo com Jean-François Botrel, "em princípios do século XX, Paris era uma das capitais da edição em língua espanhola. La Librerie Garnier Frères, las Ediciones Bouret, la Librerie Ollendorff e muitas outras editoras se lançam ativamente à publicação de obras originais ou de traduções que logo se distribuíam na Espanha e sobretudo na América Latina." A partir de fins do XIX, a produção francesa passou a disputar espaço na Espanha com a de outros países, como a inglesa, a alemã, a italiana e a norte-americana. A essa altura, a produção editorial nacional era muito vigorosa. Ver BOTREL, J. F. Libros, prensa y lectura en la España del siglo XIX. Biblioteca del libro. Madrid: Fundación Germán Sánchez Ruipírez; Pirámide, D. L., 1993, p.602. O tema do universo editorial espanhol na primeira metade do século XX foi enfocado no meu livro SOARES, Gabriela Pellegrino. Semear horizontes. 
Nesses últimos anos se operou na matéria uma mudança fundamental entre nós. As dificuldades próprias da Guerra Civil Espanhola, e as que agora emergem do conflito bélico europeu, são os dois fatores que determinaram preponderantemente o progressivo desenvolvimento da indústria livreira neste país. As novas editoras, mais que estabelecimentos industriais, são verdadeiras empresas de cultura. Os nomes principais são de todos conhecidos: Losada, Espasa-Calpe, Editorial Sudamericana, Claridad, Joaquín Gil, Joaquín Torres, Atlántida, Sopena e muitos outros. Buenos Aires se converteu assim, e por honroso desígnio, no meridiano intelectual do pensamento escrito da América Hispânica. Assim o demonstra, entre outros fatos, a última memória da Câmara Argentina do Livro, onde se afirma, com cifras subministradas pela Direção de Correios, que, durante o ano de 1942, foram remetidos ao exterior dez milhões de volumes impressos no país. ${ }^{13}$

Neste artigo, privilegiarei a esfera dos empreendimentos editoriais, deixando em segundo plano o tema das funções desempenhadas por exilados relacionadas à impressão, à ilustração, à revisão de provas, à tradução e demais tarefas que integram o trabalho editorial. Meu foco recairá sobre três das empresas mencionadas por Buonocore, as quais, criadas por espanhóis no contexto da Guerra Civil, ajudaram a revolucionar a indústria editorial argentina.

A vinda de Gonzalo Losada à Argentina antecedeu, em verdade, a Guerra na Espanha. O editor chegou a Buenos Aires nos anos 1920, como representante da editora espanhola Espasa Calpe. A partir de 1936, no entanto, a comunicação com a matriz se tornou difícil. Quando, no mesmo ano, a empresa anunciou sua simpatia por Franco, Losada não hesitou em abandonar seu posto. Em 1938, hipotecou sua casa e fundou uma editora própria, dirigida inicialmente por intelectuais de projeção como Guillermo Torre, Pedro Henríquez Ureña, Francisco Romero, Lorenzo Luzuriaga e Teodoro Becú.

Dentre as editoras fundadas na Argentina por espanhóis afinados com a causa republicana, Losada foi a que mais claramente imprimiu em seu catálogo as marcas dessa convicção política, tornando-se a grande editora dos exilados. Aí se publicaram obras, censuradas pelo regime franquista, de Rafael Alberti, Federico García Lorca e León Felipe, as quais penetraram e circularam clandestinamente na velha metrópole. ${ }^{14}$ Internalizada a cisão

13 BUONOCORE, Domingo. Libreros, editores e impresores de Buenos Aires. Buenos Aires: El Ateneo, 1944, p.122125. Tradução livre do espanhol feita pela autora do artigo.

14 Ver RIVERA, Jorge B. El escritor y la industria cultural. Buenos Aires: Atuel, 1998; parte II, La forja del escritor profesional (1900-1930). Los escritores y los nuevos medios masivos, p.33-63. De acordo com Leandro de Sagastizábal: "Na Argentina, o mundo da edição experimentou um verdadeiro take off a partir de 1936. Nesse ano começou a Guerra Civil Espanhola, que teria conseqüências diretas e indiretas sobre a atividade editorial argentina. Por um lado, muitos republicanos que se exilaram aqui se dedicaram a editar livros e, por outro, os anos da Guerra significaram uma virtual paralisia da atividade editorial na Espanha. A exígua produção tocou fundo em 1940, deixando cerca de $80 \%$ do mercado latino-americano sem abastecimento. A Argentina, que vinha se desenvolvendo nesse terreno sem pressa mas sem pausa, cobriu o oco de forma rigorosa, e se consolidou como quase exclusiva provedora de livros para a toda a região. Para dar uma idéia quantitativa do fenômeno, citaremos um 
espanhola pelas ex-colônias na América, as posições tomadas voltam a irradiar para a Espanha.

O catalão Antonio López Llausás, filho de um importante livreiro e sócio da livraria Catalonia em Barcelona, exilado na Argentina depois de passar pela França e pela Colômbia, contou com os auspícios de Victoria Ocampo, Oliverio Girondo e Alfredo González Garaño para fundar a prestigiada editora Sudamericana. Embora tenha sido pensada como um afluente da revista Sur, López Lláusas logo se converteu em principal acionista e gestor da empresa. A Sudamericana nasceu, em fins de 1938, sobre a estrutura e a reputação angariadas com a compra da Librería del Colegio - livraria e editora fundada em princípios do século XIX em frente ao Colegio Nacional de Buenos Aires, e pertencente, no início do século XX, a Joaquín e Eduardo Cabaut. Anos mais tarde, com o apoio de Francisco Porrúa, a quem o editor catalão aos poucos confiou a tarefa de selecionar os autores que integrariam o catálogo, o selo da Sudamericana marcava as edições em espanhol de diferentes pesos pesados da literatura universal - de Hermann Hesse a Ernest Hemingway, de Julio Cortázar a Gabriel García Márquez.

Todavia, o catálogo de Sudamericana era eclético. Em suas colunas, vencedores do Prêmio Nobel conviveram com escritores de auto-ajuda, e autores católicos com pensadores socialistas. Para satisfazer os gostos de diferentes públicos, a empresa fez largo uso de coleções, repetindo uma estratégia comercial que vinha se revelando bem-sucedida, no caso do mercado editorial argentino, desde a experiência da Biblioteca de la Nación. ${ }^{15}$ Dentre elas estavam Horizonte, Ciencia y cultura, Breviarios del Pensamiento Filosófic 0, Colección Infantil, Enciclopedia Agropecuaria, Credo de Pensadores, Autores Argentinos e Sur. Nos anos 1950, a Sudamericana lançou sua primeira coleção de livros de bolso, a Piragua, que seguia os passos das coleções estrangeiras Penguin Books e Austral, esta última lançada pela editora Espasa Calpe na Espanha e na Hispanoamérica.

Com os olhos pousados sobre o vasto mercado de leitores em castelhano, López Llausás estabeleceu no México a editora Hermes, uma contrapartida da Sudamericana. Também na Espanha, em parceria com a editora Emecé e a Fondo de Cultura Económica, criou a Edhasa.

A Emecé surgira na Argentina poucos meses depois da Sudamericana, em 1939, fruto do exílio espanhol. Fundada pelo recém-chegado Mariano Medina del Río, com a colaboração do acadêmico galego Alvaro de las Casas, voltou-se originalmente ao mercado de livros para imigrantes da Galícia. Mas a editora recebeu investimentos de uma importante família

dado: em um só ano (1937/8) a produção local de livros aumentou em 143\%." Cf. SAGASTIZÁBAL, Leandro de. La edición de libros en la Argentina: una empresa de cultura. Buenos Aires: EUDEBA, 1995, p.75-76.

15 Sobre a história e os significados do recurso a coleções editoriais ver OLIVERO, Isabelle. L'invention de la collection: de la diffusion de la littérature et des savoirs à la formation du citoyen au XIXe siècle. Paris: Éditions de I'IMEC; Édition de la Maison des Sciences de l'Homme, 1999. 
argentina - os Braun Menéndez -, responsáveis pela mudança de rumos. A empresa passou a privilegiar livros clássicos destinados às camadas altas e cultas, com orientação anglófila e católica. A coleção Grandes Novelistas, inaugurada em 1948, reuniu autores como Albert Camus, Alberto Moravia e Graham Greene. Publicou, também, quase toda a obra de Jorge Luis Borges. Foi justamente o hoje celebrado escritor argentino quem, com Adolfo Bioy Casares, dirigiu a longa coleção de novelas policiais da Emecé, El Séptimo Círculo.

Ao contrário de Losada, o fato de Emecé e Sudamericana terem sido fundadas no calor dos confrontos políticos na Espanha não se refletiu em seus catálogos. De todo modo, ambas desempenharam um papel central para que a produção editorial argentina ultrapassasse as fronteiras nacionais à conquista dos mercados hispano-americano e espanhol, seguida, a considerável distância, pelas editoras mexicanas.

\section{Editores espanhóis no México}

Embora o México possuísse ateliês de imprensa desde princípios da colonização, foi no século XIX, impulsionadas pelo ideário liberal e a expansão do mercado, que as tipografias e editoras ganharam alento no país. Nas décadas que se seguiram à independência, empreendedores como Mariano Galván Rivera, Ignácio Cumplido e José Mariano Lara dedicaram-se à publicação de folletos, calendários, jornais e coleções de livros, estabelecendo as bases de uma indústria editorial nacional. ${ }^{16}$

Nos anos 1920, as políticas culturais e educacionais dos governos pós-revolucionários ajudaram a criar novos mercados para a circulação de impressos, estimulando a formação de novas gráficas e editoras. Os acontecimentos que abalaram o comércio de livros com a Espanha, na década seguinte, tornaram esses mercados ainda mais promissores a novas iniciativas.

Muitos refugiados da Guerra Civil Espanhola encontrariam nesse campo, como ocorreu na Argentina, oportunidades de inserção profissional. A editora Fondo de Cultura Económica, fundada como já mencionado em 1934, desempenhou um papel particularmente importante nesse sentido. Um núcleo expressivo de refugiados ajudou a dar corpo à empresa, atuando nas áreas de impressão, revisão de provas, ilustração, tradução, ou ainda como editores ou diretores de seção.

O catálogo da Fondo também expressava o vínculo da editora com a comunidade espanhola no exílio. Foram publicadas diversas obras de filósofos, literatos e artistas ligados à Casa de España en México, idealizada

16 SUÁREZ DE LA TORRE, Laura. (org.) Constructores de un cambio cultural: impresores-editores y libreros en la ciudad de México, 1830-1855. México: Instituto Mora, 2003, p.183-251. 
por Cosío Villegas. O repertório que daí resultou primava pelas memórias nostálgicas dos poetas no exílio, como España del éxodo y del llanto, de Leon Felipe; estudos da poesia e da dramaturgia espanholas e produções literárias e filosóficas de autores de projeção, como José Gaos e Menéndez Pidal. Essas obras com freqüência expressaram um olhar, à distância, de redescoberta da terra natal.

Como na Argentina, muitos refugiados encontraram no México a possibilidade de iniciar uma nova empresa editorial. Também aqui procurei apenas chamar atenção para algumas experiências que considero expressivas de um amplo conjunto de trajetórias, o qual demandaria uma análise mais extensa.

Dentre as editoras que assim tiveram origem, está a Editorial B. Costa Amic, responsável por um catálogo de obras em diferentes idiomas - do catalão e o espanhol ao francês e o inglês. Ao lado de B. Costa Amic, outras empresas reproduziram, no México, a prática de editar em idioma regional. O Club del Libre Catalá e a Comunitat Catalana de Mexic permaneceram fiéis ao catalão, enquanto a Vasca Ekin editou livros em basco, além do castelhano.

Os títulos ofertados tiveram perfis muito variados, nem sempre traduzindo as opções políticas que haviam provocado a cisão da Espanha. A Editorial Leyenda, por exemplo, especializou-se em livros de arte e de história. A Editorial Sêneca, por sua vez, voltou-se a livros de ciências, medicina, arte, filosofia, clássicos espanhóis e textos didáticos. Com catálogos diversificados, ambas conquistaram considerável envergadura comercial, ao lado de algumas das casas igualmente fundadas por refugiados, como UTEHA (Unión Tipográfica Editorial Hispano Americana) e a Grijaldo.

Foi também esse o caso da editora ERA, criada em 1960, sobre as bases da livraria estabelecida pelo exilado espanhol Tomás Espresate na calle Madero, no centro da Cidade do México, nos anos 1950. Seus filhos Jordí e Francisco Neus Espresate, proprietários de uma gráfica na mesma cidade, uniram-se aos espanhóis Vicente Rojo e José Azorín para, no espaço da livraria, fundar ERA, nome composto a partir das iniciais dos três sobrenomes envolvidos. O catálogo de ERA deu ênfase aos textos críticos, associados ao pensamento marxista e às vanguardas artísticas, apresentados aos leitores sob capas que revelavam o cuidado estético e gosto experimental do desenhista e sócio Vicente Rojo. Autores como Gramsci e Isaac Deutchster foram editados ao lado de expoentes das idéias e letras mexicanas, como Pablo González Casanova, Fernando Benítez, Carlos Fuentes e José Emilio Pacheco. Escritores caribenhos e hispano-americanos também foram destaques de ERA, dentre os quais José Lezama Lima, Aimé Césaire e Augusto Salazar Bondy.

A atuação de ERA concorreu para alavancar a produção editorial mexicana em meados do século XX, de forma que esta também pudesse 
disputar com a vigorosa indústria argentina mercados no continente e no além-mar. Muitas das obras publicadas por ERA estavam censuradas na Espanha franquista, mas não faltaram mediadores dispostos a fazer com que chegassem, por caminhos subterrâneos, aos leitores inconformados da velha metrópole.

\title{
Considerações finais
}

Em uma conferência sobre "La industria editorial y la cultura", proferida na Universidade Nacional Autônoma do México, em 1947, para os delegados da II Conferência da Unesco, Daniel Cosío Villegas relativizou o papel desempenhado pela Guerra Civil Espanhola no desenvolvimento da indústria editorial de certos países hispano-americanos.

\begin{abstract}
Se na Argentina, como no Chile e no México, não existiu uma verdadeira indústria editorial até cerca de 10 ou 12 anos atrás, não é exclusivamente, como se afirmou com tanta insistência, pelo simples fato de que a Guerra Civil Espanhola de 1936 nos deu a oportunidade de nos lançarmos a imprimir livros industrialmente sem uma concorrência espanhola que, seguramente, nos teria esmagado se a Espanha não tivesse sofrido o colapso que sofreu em conseqüência dessa guerra. Muito mais importante foi que nessas datas começava-se a colher os frutos da ação educativa mais velha e mais pausada no Chile e na Argentina, ou mais recente mas vigorosa no México, onde é evidente que houve uma elevação da vida material e espiritual dos grandes grupos humanos nos últimos vinte anos. Mas isso não quer dizer, é claro, que não haja ainda muito por fazer, e que a situação atual não crie para o editor que trabalha industrialmente uma atmosfera de desalento, quando não de desolação. ${ }^{17}$
\end{abstract}

Parece-me valiosa a preocupação expressa pelo editor, ao destacar as condições internas que permitiram à Argentina, ao Chile e ao México aproveitar a "triste" oportunidade aberta pela conjuntura internacional ao desenvolvimento de sua indústria livreira. Entretanto, penso que o debate sobre os significados da Guerra Civil na Espanha para o mercado editorial hispano-americano ultrapassa o questionamento acerca das responsabilidades pelo considerável desempenho das empresas nacionais a partir dos anos 1930.

A suspensão temporária da concorrência espanhola e a leva de refugiados da Guerra que aportou, entre outros, na Argentina e no México, trazendo consigo velhos conhecedores do mundo dos livros e da edição, propiciaram novas formas de mediação e reelaboração das idéias em circulação na América Espanhola. Coleções de livros foram pensadas de forma a atender a demandas específicas dos leitores desta região do Globo - no

17 Cosío VILLEGAS, Daniel. La industria editorial y la cultura. In. Extremos de América. México: Fondo de Cultura Económica, 2004, p.244. Tradução livre do espanhol feita pela autora do artigo. 
que diz respeito ao conteúdo, aos critérios de organização, ao formato e ao preço -, ainda que uma parcela da produção mirasse os mercados no além-mar.

Escritores hispano-americanos puderam estabelecer diálogos mais diretos com os empresários da edição, suavizando as dificuldades enfrentadas por escritores do século XIX e princípios do século XX, à mercê das decisões dos distantes editores espanhóis ou franceses. ${ }^{18}$

Por fim, para mencionar algumas das muitas implicações das drásticas reviravoltas políticas na Europa, a atuação de exilados espanhóis em diferentes níveis da arte da edição na Argentina e no México transferiu práticas, conceitos e sensibilidades aos companheiros de trabalho que se iniciavam no métier, aproveitando as oportunidades de emprego oferecidas por uma indústria que não era nova em seus países, mas que se expandia naquele momento.

Todas essas possibilidades ganharam vigor em virtude da Guerra na Espanha, apesar da "atmosfera de desalento" e do ainda muito por fazer a que se referiu Cosío Villegas.

É, portanto, nesse âmbito "qualitativo" que eu acredito podermos encontrar férteis e ainda inexplorados caminhos de pesquisa em torno da temática da internalização da indústria editorial espanhola por determinados países da América de fala espanhola, como parte do rastro histórico deixado pela Guerra Civil.

18 O escritor argentino Hugo Wast (1883-1962), pseudônimo de Gustavo Martínez Zuviría, constitui uma referência de sucesso editorial na primeira metade do século XX. Os 33 livros que publicara até 1946 somavam 312 edições, nesse ano, e um total de 1.896.000 exemplares vendidos. A história da publicação de seu primeiro romance, Alegre, expressa as tortuosas possibilidades colocadas para escritores hispano-americanos da época, embora, no caso de Hugo Wast, a história tenha tido um desenrolar feliz. A primeira edição de Alegre foi feita pelo editor Fernando Fe, em Madri, em 1905. Saturnino Calleja realizou então, entre 1908 e 1912, mais três edições da obra, reduzindo o texto para fazer caber num volume os dois tomos originais. Em 1914, a livraria Paul Ollendorff publicou em Paris, na coleção espanhola, uma reimpressão do texto. Foi então relançado pela livraria Nilsson, de Paris, em copiosa edição. A revista La llustración Artística, editada em Barcelona por Montaner y Simón, publicou Alegre com muitas ilustrações. Atualmente, a editora Plus Ultra, sediada em Buenos Aires, detém os direitos de edição da obra. 